Canadian

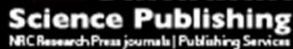

Canadian Geotechnical Journal Revue canadienne de géotechnique

\title{
Microfabricated sol-gel relative humidity sensors for soil suction measurement during laboratory tests
}

\begin{tabular}{|r|l|}
\hline Journal: & Canadian Geotechnical Journal \\
\hline Manuscript ID & cgj-2016-0419.R1 \\
\hline Manuscript Type: & Article \\
\hline Complete List of Authors: & $\begin{array}{r}\text { Cardoso, Rafaela; Universidade de Lisboa Instituto Superior Tecnico, } \\
\text { DECivil } \\
\text { Sarapajevaite, Gabriele; INESC-MN Microsystems and Nanotechnologies, ; } \\
\text { Kauno Technologijos Universitetas, Department of Silicates } \\
\text { Korsun, Oleksandr; INESC-MN Microsystems and Nanotechnologies, } \\
\text { Cardoso, Susana; Universidade de Lisboa Instituto Superior Tecnico, } \\
\text { Physics; INESC-MN Microsystems and Nanotechnologies, } \\
\text { Ilharco, Laura; Universidade de Lisboa Instituto Superior Tecnico, DEpto } \\
\text { Enga Química e Biológica; Universidade de Lisboa Centro de Quimica-Fisica } \\
\text { Molecular, }\end{array}$ \\
\hline Keyword: & $\begin{array}{l}\text { Microfabricated interdigitated electrodes, suction, humidity sensors, } \\
\text { relative humidity, unsaturated soils }\end{array}$ \\
\hline \multicolumn{2}{|c}{} \\
\hline
\end{tabular}


Technical note

\section{Microfabricated sol-gel relative humidity sensors for soil suction measurement during laboratory tests}
Rafaela Cardosorafaela@civil.ist.utl.pt
Instituto Superior Técnico (IST), Lisbon University, Lisbon, Portugal
Civil Engineering Research Innovation and Sustainability (CERIS), Institute of Construction, Structures and Territory of IST (ICIST), Lisbon, Portugal

Gabriele Sarapajevaite_sarapajevaite@yahoo.com

INESC-MN Microsystems and Nanotechnologies, Lisbon, Portugal

Oleksandr Korsun_ korsun.oleksandr@gmail.com

INESC-MN Microsystems and Nanotechnologies, Lisbon, Portugal

Susana Cardoso_scardoso@inesc-mn.pt

Instituto Superior Técnico (IST), Lisbon University, Lisbon, Portugal

INESC-MN Microsystems and Nanotechnologies, Lisbon, Portugal

Laura Ilharco lilharco@ist.utl.pt

Instituto Superior Técnico (IST), Lisbon University, Lisbon, Portugal

CQFM Centro de Química-Física Molecular, IST, Lisbon, Portugal

Corresponding author:

Rafaela Cardoso, $\mathrm{PhD}$,

Assistant Professor at DECivil, IST, Lisbon University

CERIS, ICIST, IST, University of Lisbon

Av Rovisco Pais, 1

1049-001 Lisbon

PORTUGAL

Phone: +351218418265 / Fax: +351218418427

rafaela@civil.ist.utl.pt 


\title{
Microfabricated sol-gel relative humidity sensors for soil suction measurement during laboratory tests
}

\begin{abstract}
Currently there are no small sensors to be incorporated inside soil samples for laboratory testing, to monitor water transport during loading. This is an important limitation for a better understanding of the hydro-mechanical coupled behaviour of soils. A sol-gel relative humidity sensor $(11 \mathrm{~mm} \times 11 \mathrm{~mm})$, microfabricated in clean room environment, was conceived to be incorporated in soil specimens during standard laboratorial tests. The sensor operates based on changes in electrical resistivity detected by a cerium doped silica-titania film deposited using a sol-gel technique over interdigitated aluminium electrodes spaced 300 $\mu \mathrm{m}$. To the best of authors knowledge, sol-gel sensors for relative humidity measurement have never been used in soils therefore this is a novel application.

The water retention curve of compacted kaolin was measured with the sensors and compared with the curve found using water dewpoint potentiometer WP4-C. The sensors were also tested incorporated in an oedometer cell, in which load was applied under vapour equilibrium. It was possible to detect the increment of the degree of saturation during compression. The use of the developed sensors incorporated in soils is considered acceptable for suction ranges between $1 \mathrm{MPa}$ and $10 \mathrm{MPa}$, which extends the suction interval covered by tensiometers, normally operating up to $2 \mathrm{MPa}$. Although the sensors require improvements in terms of sol-gel deposition and calibration protocol, the results confirm their scientific potential for being used in testing and characterization of unsaturated soils.
\end{abstract}

Key words: Microfabricated interdigitated electrodes, humidity sensors; suction; relative humidity; unsaturated soils; oedometric compression 


\section{Microfabricated sol-gel relative humidity sensors for soil suction measurement during laboratory tests}

\section{INTRODUCTION}

An important limitation for a better understanding of the hydro-mechanical coupled behaviour of soils is the inexistence of small sensors to be incorporated inside soil samples for laboratory testing, to monitor water transport during load application. This knowledge has several engineering applications where the unsaturated behaviour of soils must be considered. Relevant examples for which this behaviour must be known are the prediction of deformations caused by wetting or drying, the study of soil-atmosphere interaction, or the development of tools to model unsaturated flow of water, gas and contaminants in both liquid and gas phases.

There are several sensors commercially available that can be used for soil suction measurement, or for its indirect estimation through measuring water content. Some examples are tensiometers (Woodburn and Lucas 1995; Tarantino and Mongiovì 2003; Lourenço et al. 2011), psychrometers (Truong and Holden, 2011), electrical resistivity probes, magnetic and capacitance sensors (Fares et al. 2011; Vaz et al. 2013) and frequency and time domain resistivity (FDR and TDR, respectively) probes (Kizito et al. 2008). However, the existing sensors cannot be incorporated in soil specimens during standard laboratory tests mainly due to their large size, low operation speed or limited suction measurement ranges. These problems inspired the development of the sol-gel sensors presented in this work.

Tensiometers were introduced inside soil specimens in oedometer and triaxial cells (Lourenço et al. 2011), but their use is limited because the sensors are relatively large and the soil must be in perfect contact with the sensor through a ceramic porous disk previously 
saturated with water (Tarantino and Mongiovì 2003). The minimum size of these sensors is 1 $\mathrm{cm}$ in diameter and the maximum suction measured is between $2000 \mathrm{kPa}$ and $20 \mathrm{kPa}$. Since they are placed in the walls of the specimens (top or bottom in case of oedometers or triaxial tests, or in the lateral walls in case of triaxial cells), these sensors do not allow studying water flow inside the specimen.

Some popular sensors used in soils measure relative humidity of the air in the soil pores. Basically they incorporate gypsum blocks, polymers or tissues placed in contact with the soil (Fredlund and Rahardjo 1993; Keyhani 2001; Albrecht et al. 2003). At equilibrium the resistivity changes of the contact material can be related with relative humidity after calibration. Besides sensor size, this method has the disadvantage of being affected by hydraulic hysteresis of the material in contact with the soil, which changes its properties irreversibility when it is fully saturated. Another possibility is to measure soil water content, either volumetric or gravimetric, which can be related with suction if the water retention curve of the soil is previously known (Romero 2001). Filter paper is another example in which soil suction is measured through changes in water content of the paper. These changes are related with suction through the water retention curve of the filter paper (Fredlund and Rahardjo 1993, for example). The perfect contact between the soil and the sensing material is an important limitation of these sensors and they must be calibrated to consider the void ratio of the soil.

There are several types of sensors that can work as relative humidity sensors in different applications. They are traditionally been used in air. Optical fibres and resistive or capacitive sensors are the most widespread (Traversa 1995; Rittersma 2002). Thin ceramic films made of $\mathrm{MgAl}_{2} \mathrm{O}_{4}, \mathrm{MgFe}_{2} \mathrm{O}_{4}, \mathrm{Fe}_{2} \mathrm{O}_{3}$ or composite oxides with $\mathrm{TiO}_{2}$ are common resistive sensors, as well as thick films sensors made of alumina or titania oxide and $\mathrm{SnO}_{2}$ mixtures, and sol- 
gel sensors with different compositions, from purely inorganic to organic-inorganic composites (Kozhukharov et al. 2013, 2015; Yuan et al. 2011; Sukhyy et al. 2015).

To the best of authors knowledge, sol-gel sensors for relative humidity measurement have never been used in soils. The sensors presented in this paper are resistive sensors measuring relative humidity using a sol-gel film, microfabricated in clean room environment and developed to be incorporated in soil specimens during standard laboratory tests, to work in direct contact with the material. They were developed intending to have fast response (less than 1 minute), low capacitance and low hysteresis. The working principle of the sensors, as well as their calibration, is briefly presented. The prototypes were incorporated in compacted specimens of kaolin and used to measure the water retention curve (WRC) and tested in an adapted oedometer cell under stress increments. The main results are presented in this paper and allowed defining the operation range of the sensors and their validation.

\section{SOL-GEL SENSORS}

The sensor developed is a resistive sensor and consists in $100 \mu \mathrm{m}$ wide, $300 \mathrm{~nm}$ thick interdigitated aluminium electrodes with $100 \mu \mathrm{m}$ width and spaced $300 \mu \mathrm{m}$, deposited on a glass substrate (Figure 1.a). It was microfabricated in clean room environment to achieve these small dimensions with precision. The sensor's footprint area is $11000 \mu \mathrm{m} \times 11000 \mu \mathrm{m}$ $(11 \mathrm{~mm} \times 11 \mathrm{~mm})$ and the overall thickness is around $800 \mu \mathrm{m}$. This geometry offers the advantage of being easily customised and adapted for any shape, according to the sample scale. The electrodes were covered by a Cerium doped silica-titania film deposited using a sol-gel technique. The procedure followed for sol-gel fabrication was adapted from the works of Kozhukharov et al. $(2013,2015)$. The composition is $60 \%$ titania and $40 \%$ silica, using as precursors titanium (IV) n-butoxide (TBOT) and trymethylsiloxy-terminated polydimethylsiloxane (PDTS), respectively. The catalyst and Ce dopant was diammonium 
cerium(IV) nitrate or ceric ammonium nitrate (CAN), which has a catalytic effect as a Lewis acid in the hydrolysis of TBOT, and acts also as oxidant of the siloxane chains of PDTS. Basically, the gel is sintered at a relatively high temperature (above $300^{\circ} \mathrm{C}$ ) and forms a stiff cover above the electrodes (Figure 1.b). For simplicity, it will be named as sol-gel. This coating is responsible for the required sensor sensitivity to water, because the water molecules are adsorbed by the sol-gel layer and therefore the electrical conductivity of this material increases. It is measured by the electrodes. A photograph of one of the sensors used is presented in Figure 1.c, where the electrodes covered by the sol-gel and the electrical wires necessary for resistivity measurements can be seen. The sol-gel layer has different shades of white because the thickness is variable above the sensing area. This is inevitable and is caused by the deposition procedure (Kozhukharov et al. 2015). The quantity of water molecules available depends on the relative humidity of the environment where the sol-gel sensor is placed. It will be the same as the surrounding soil once equilibrium is reached. Such process is illustrated in Figure 1.d. This equilibrium process involves the migration of water mainly in gas phase (RH exchanges, in Fig 1.d), which is inevitable after inserting the sensor into the soil. The wetting or drying effect of inserting the sensor may be neglected if the volume of sol-gel is small when compared with that of the soil, which is the case.

After sintering at $400^{\circ} \mathrm{C}$, the resulting sol-gel coating is a porous material, as observed in the scanning electron microscope (SEM) photograph presented in Figure 2.a. The pore structure is bimodal: macropores with average diameter of $100 \mathrm{~nm}$ and micropores (average pore diameter below $2 \mathrm{~nm}$ ) within spherical particles with almost uniform sizes (diameters around $1 \mu \mathrm{m})$. This porous structure, assessed by nitrogen adsorption-desorption isotherms, is most suitable for humidity sensing. It is similar to the one recently obtained for sensors prepared using a microporous organic polymer based on 1,3,5-trihydroxybenzene (Jiang et al. 2014).The thickness of the cover is less than $100 \mu \mathrm{m}$. Sensor sensitivity depends on the 
diameter of the sol-gel pores and is associated to capillarity effects as described by Laplace equation,

$$
r_{k}=\frac{2 \gamma M}{\rho R T \ln \left(\frac{P}{P_{S}}\right)}
$$

where $r_{k}$ is the Kelvin radius of the cylindrical open pores (open at both ends), $\gamma$ is the surface tension of water $\left(72.75 \times 10^{-3} \mathrm{~N} / \mathrm{m}\right.$ at $\left.20{ }^{\circ} \mathrm{C}\right), M$ is the molecular mass of water $(18.016$ $\mathrm{kg} / \mathrm{kmol}), \rho$ is the density of pure water $\left(998 \mathrm{~kg} / \mathrm{m}^{3}\right.$ at $\left.293 \mathrm{~K}=20^{\circ} \mathrm{C}\right) . P$ is the water vapour pressure and $P_{s}$ is the water vapour pressure at saturation (the ratio $P / P_{s}$ is the relative humidity, $\mathrm{RH}), R$ is the gas constant $(8.314 \mathrm{~J} /(\mathrm{mol} \mathrm{K}))$ and $T$ is the absolute temperature. The relationship between suction $s$ and relative humidity is given by Kelvin's law,

$$
s=-\frac{R T \rho}{M} \ln (R H)
$$

where all the constants were explained above. Using equations 1 and 2, for the average diameter of sol-gel macropores of $100 \mathrm{~nm}$ (see Fig. 2.a) and $20^{\circ} \mathrm{C}$, the relative humidity is $80.6 \%$ and the corresponding suction is $29.1 \mathrm{MPa}$ ((theoretical minimum relative humidity). This marks the maximum RH detected by the sol-gel sensors and explains the large RH operation range of such type of sensors (Rittersma 2002).

It is worth to note that suction computed from RH using Equation 2 is total suction, which is the sum of matric and osmotic components (Fredlund and Rahardjo 1993). In this paper only total suction is considered because the sol-gel sensors adsorb water molecules independently from being or not in contact with the soil, in particular because sol-gel pores are smaller than the pores of the clayey soil investigated and therefore the continuity of the gas phase in the two porous medium can be ensured. 
SOIL SAMPLES PREPARATION

Several samples of compacted kaolin were prepared to be used for sensors calibration and validation, by measuring the water retention curve and testing their response under oedometric loading. The samples were compacted with void ratio of 0.9 and water content of $25 \%$. This procedure allowed having soft samples with high void ratio, helpful in sensors installation (done by pushing the sensors into the soil). Distilled water was used to minimize osmotic effects. White kaolin was used, having $68 \%$ in mass of particles with silt size (diameters between $0.075 \mathrm{~mm}$ and $0.002 \mathrm{~mm}$ ) and $31 \%$ with clay size (diameters less than $0.002 \mathrm{~mm}$ ). Solid volumetric weight is $26.1 \mathrm{kN} / \mathrm{m}^{3}$. Liquid limit is $52 \%$ and plasticity index is $22 \%$, therefore the material classifies as highly plastic silt $(\mathrm{MH})$ according to the Unified Soil Classification System.

The water retention curve of the compacted material was measured using water dewpoint potentiometer WP4-C (WP4-C, 2003) and will be presented later in the paper. Suction corresponding to the water content at preparation is $0.8 \mathrm{MPa}$. Figure 2.b presents a SEM photograph of the compacted material. The comparison between the textures of the sol-gel and of the compacted clay studied, respectively in Figures 2.a and 2.b, clearly shows the difference between the artificial and the natural porous materials, because there is a large contrast in particle size and shape, as well as in regularity.

\section{SENSORS CALIBRATION}

The sensors were calibrated using compacted soil samples prepared specially for this purpose. The samples, compacted as previously described, were subjected to controlled wetting or drying (constant temperature $21 \pm 2{ }^{\circ} \mathrm{C}$ ), in order to have a known relative humidity, or suction. The RH of the samples was applied using the vapour equilibrium technique, using unsaturated salt solutions (OIML R 121, 1996). Equilibrium was controlled 
by measuring changes in water content (equilibrium considered to be reached when mass changes between readings was below $0.5 \%$ ) and final suction was measured by WP4-C. Table 1 presents the details of these samples, namely their water content $w$, suction $s$ (measured using WP4-C) and corresponding relative humidity (computed from suction using Eq. 2). The $100 \%$ relative humidity was simulated using a drop of water. The RH interval was chosen to cover a large range to help identifying the operating range for the sensors.

The sensors impedance was measured when they were gently pushed against the samples, to ensure direct contact between the soil and sol-gel. This allowed obtaining the plots impedance versus relative humidity presented in Figure 3 . The sequence of measurements was done starting from the driest to the wettest samples (wetting path) and then returning back to the driest one (drying path). This procedure allowed quantifying the hysteresis of the sol-gel sensors when operating in soils. Also, it accounts with possible sol-gel pore clogging with clay particles, as it may affect sensors' speed and sensitivity. This clogging effect cannot not be detected if calibration would be done using salt solutions, and therefore using soil pieces is considered to be more suitable to calibrate such sensors because they are operating in similar environments.

Current was measured applying constant DC voltage of $2.1 \mathrm{~V}$, therefore resistance was found using Ohm law. The voltage/current source Keithley Impedance meter, Model 2401, was used for the measurements. The response time of the sensors, or the time necessary for the signal to become stable, was around 2 minutes. The delay observed is explained by the capacitance of the sensors.

Five sensors were calibrated using this procedure and the same samples were used for all. The average values of their readings are presented in Figure 3. This figure also includes the error bars computed considering the maximum and minimum values measured, and the equation for the bi-linear relationship found to best fit the average values (defined from 
relative humidity between $100 \%$ and $97 \%$ and for relative humidity lower than $97 \%$ ). The highest sensitivity (slope of the lines) is intended when developing sensors and this occurs for the line defined for the highest RH.

As already said, soil samples were used for calibration instead of salt solutions to account for possible sol-gel contamination with the fine particles of the clay (pore clogging), due to the contact between the two materials during operation. Some contamination was observed, which is believed to be responsible for the hysteresis registered in the high RH range (different impedance for the same RH when following wetting or drying paths), as presented in Figure 3. In the literature such kind of sensors is calibrated against air with known controlled relative humidity and their hysteresis is irrelevant (Kozhukharov et al. 2015). This is explained by the homogeneous pore dimensions of sol-gel. Some hysteresis in sensor readings was observed against the clay because the measurements on each hydraulic path were different. Nevertheless, a unique calibration curve was adopted for simplification, defined considering all the values found for all samples. Some of the points on drying were outside the error bars defined using the points measured on wetting. However they still could be fitted in acceptable manner by this unique bilinear relation adopted for calibration. Therefore, in average, the hysteresis in the sensors readings against the soil can be considered irrelevant. This will be discussed later in the analysis of sensors performance measuring the WRC.

The comparison of the different sensors shows some differences in terms of sensitivity and transition point. This can be explained by sol-gel heterogeneity (see the indication in Figure 1.c), which is associated to the deposition procedure adopted (Kozhukharov et al. 2013). The transition point in the bi-linear relationship found for each sensor is near the relative humidity corresponding to the maximum theoretical value that can be detected by sol-gel (around $81 \%$ ) 
prepared to have the pore distribution already discussed. Further details on sensors calibration can be found in Cardoso et al. (2016).

In order to confirm whether the sensors sensitivity would be affected by the homogeneity of the sol-gel, a complementary study was performed in which one sensor having the electrodes without the sol-gel coating was calibrated directly against clay samples (only following a wetting path). The comparison of the readings between the sensors with sol-gel coating (average values) and those using this uncovered sensor is presented also in Figure 3.

It can be seen that the transition between the two linear relationships is very smooth for the sensor without sol-gel. Being this slope a direct sensitivity parameter, the larger slope found in the high $\mathrm{RH}$ range for the sol-gel sensors indicates that sol-gel enhances the sensor's sensitivity in this range. For this reason the sol-gel coated electrodes can be considered better than using only the bare electrodes. In addition, this result appears to indicate that the deviations found between the readings of all sensors in this RH range can be explained by differences in the homogeneity of sol-gel coating above their sensing area. This is not a concern because the calibration curve of each sensor must be used for its own data interpretation, as it is done for any other sensing devices. For this reason, the calibration curves of each one of the sensors used in the remaining paper are presented in Table 2.

\section{PERFORMANCE MEASURING WATER RETENTION CURVE}

The sensors were tested during the measurement of the water retention curve, WRC. The purpose was to compare the suction values measured with the sensor and with WP4-C. Only one sensor was tested. It was pushed against a soil sample and wrapped with compacted soil to minimize soil disturbance, as shown in Figure 4. This procedure would cast in the sensor, preventing its detachment from the soil during drying. The soil sample was prepared as 
previously described. The calibration curve of the sensor used is indicated in Table 2 ("WRC sensor").

The sample and sensor were placed inside a WP4-C cup, as shown in Figure 4. Care was taken to fit the electrical wires inside the cup and make them accessible for the measurements without touching or moving the sample. For the WRC measurements, the sample was let dry in a controlled manner, followed by partial wetting by adding small drops of water. Equilibrium time between readings was $24 \mathrm{~h}$. The curves relating sensors impedance with soil water content are presented in Figure 5.a. Some hysteresis in the sensors' readings can be seen for water contents below $17 \%$. Hysteresis is also observed for suction values larger than $1 \mathrm{MPa}$ (suction measured by WP4-C) as shown in Figure 5.b, presenting impedance versus suction. This corresponds to relative humidity values larger than $98 \%$. The hysteresis observed varies between $1 \%$ and $2 \%$ in terms of $\mathrm{RH}$, which is similar to the values observed in other RH sensors, see for example the manual of HMT337 (2004). Such values agree with those previously observed in the calibration, presented in Figure 3. Based in this, the hysteresis in sensors readings was neglected in the rest of the paper.

Suction values computed from the impedances measured, using the sensor calibration curve, can now be compared with those from WP4-C. The comparison is presented in Figure 6. The water retention curves presented in this figure were adjusted from WP4-C readings using Equation 3, proposed by Van Genuchten (1980),

$$
S_{r}=\left[1+\left(\frac{s}{P}\right)^{\frac{\lambda}{1-\lambda}}\right]^{-\lambda}
$$

where $S_{r}$ is the degree of saturation, $s$ is suction, $P$ is the pressure corresponding to the air entry value and $\lambda$ is a fitting parameter (Drying branch: $\mathrm{P}=0.67 \mathrm{MPa}$ and $\lambda=0.35$; Wetting branch: $\mathrm{P}=0.30 \mathrm{MPa}$ and $\lambda=0.33$ ). They were included to indentify the region where the experimental points would be expected. 
As shown in Figure 6, the points found using the sensors fit well the region contained by the curves. Almost no hysteretic effect is observed when using the sensors for measuring the water retention curve (squares in Fig 6), probably because the calibration curve of the sensors for wetting and drying is the same. However, it is worth to note that the points corresponding to WP4-C readings (triangles in Fig 6) are not much affected by hysteresis either. The proximity of the points found using WP4-C values and those computed from impedance measurements is quite acceptable, except for suctions below $1 \mathrm{MPa}$ and above $10 \mathrm{MPa}$. Figure 6 includes the suction measured in two specific points using a tensiometer from Durham University, UK (Lourenço et al. 2011). Tensiometers operate in the suction range below $1 \mathrm{MPa}$, for which water dewpoint potentiometers present some limitations (Leong et al. 2003; Cardoso et al. 2007). The proximity of the WP4-C and tensiometer readings confirm that this equipment provides acceptable readings for suctions between $0.5 \mathrm{MPa}$ and $80 \mathrm{MPa}$. Based on these results, it can be concluded that the sensor readings below $1 \mathrm{MPa}$ must not be considered. Consequently, the operation interval for the sensor used is considered to be between $10 \mathrm{MPa}$ and $1 \mathrm{MPa}$. This interval is inside the calibration interval of the sensors (values in Table 1 and Figure 3), even a bi-linear curve is necessary (equations in Table 2).

The upper value of $10 \mathrm{MPa}$ is below the maximum theoretical value of $28 \mathrm{MPa}$, estimated considering the minimum RH that could be detected by sol gel computed using the diameter of the sol-gel pores. The fact that it was slightly lower may be explained by some changes in void ratio occurring during drying, therefore affecting calibration. Such topic requires further investigation. Nevertheless, the maximum value measured, $10 \mathrm{MPa}$, it larger than the $1 \mathrm{MPa}$ measured with tensiometers or the 1.5 MPa applied with high air entry value porous stones in axis translation technique (Tarantino et al. 2011). Sol-gel sensors therefore may be used in complement to the other techniques to cover a larger suction interval. 


\section{PERFORMANCE UNDER OEDOMETRIC LOADING}

Another sensor, identified in Table 2 as "Oedometer sensor", was incorporated inside a soil sample for suction measurement during loading. Such is considered to be the final test to investigate if the sensors can operate inside soil samples and if the readings are stable along time. This test was performed in one adapted oedometric cell.

The sensor was inserted in the soil horizontally and near the bottom of the cell to prevent sensor breakage due to loading. This location and orientation also allow neglecting the compressibility of the sensor (stiffer than the soil because it is a very thin sol-gel film above glass). This also avoided perturbation from eventual drying or wetting near the upper boundary (Figure 7.a). A very thin soil layer was left below to promote a better support for the sensor. The sensor was installed in the sample before vapour equilibrium, because it is when the soil was soft and installation was easier. Both sample and porous stones were placed in vapour equilibrium before starting the test.

Two soil samples were tested: a control sample and a sample with the sensor, both compacted with $\mathrm{w}=25 \%$ and $\mathrm{e}=0.9$ inside oedometer rings $(5 \mathrm{~cm}$ diameter, $2 \mathrm{~cm}$ height, initial void ratios of 0.893 and 0.903 for the control and the sensor samples, respectively). At compaction, suction is $\mathrm{s}=1.0 \mathrm{MPa}$ and $\mathrm{RH}=99.3 \%$ (at $21^{\circ} \mathrm{C}$ ). This suction is at the lower limit range of sensors operation; however it was necessary to keep the same soil conditions as those used in sensors calibration, because resistive sensors are sensitive to soil structure (Vanapalli et al. 1999; Romero 2013, for example). After preparation the samples were dried by vapour equilibrium to $5 \mathrm{MPa}$. This value corresponds to the middle value of the sensors operating interval. Because the soil was going to be compressed, suction was expected to decrease and by this manner the sensor would be operating inside the range for the entire test.

Equilibrium was considered to be reached when the mass changes were below $0.1 \mathrm{~g}$ (changes in water content of $0.2 \%$ ). Final water content of the samples was $10.3 \%$. Corresponding 
suction is 3.7 MPa, considering the drying branch of the WRC (Fig. 6). For the sample where the sensor was installed, the impedance was measured to check suction before the test. This value was 3.9 $\mathrm{MPa}$, similar to the value expected using the WRC.

After this initial drying the samples and porous stones were placed in the oedometer cells and kept in vapour equilibrium for $24 \mathrm{~h}$ before starting load application. $\mathrm{A} \mathrm{NaCl}$ solution with $64.71 \mathrm{~g} / \mathrm{L}(\mathrm{OIML} \mathrm{R} 121,1996)$ was used, applying $\mathrm{RH}=96.4 \%\left(\mathrm{~T}=21^{\circ} \mathrm{C}\right)$ and $\mathrm{s}=5 \mathrm{MPa}$. During the entire tests, the oedometer cell was kept in a closed environment, intending to prevent significant RH changes caused by interaction with the laboratory atmosphere (drier than the soil because $\mathrm{RH}=54 \%$ and temperature was around $19^{\circ} \mathrm{C}$ ). It was achieved by involving the oedometric cells with a plastic film linked to a bottle with the same salt solution. Water content was allowed to change during this and all stages of the tests, however the changes are not expected to be large because of the low initial suction chosen.

Stress increment in each step doubled that of the previous (0-50-100-200-400-800 kPa) until reaching $1200 \mathrm{kPa}$. Unloading was done in two steps. The test with the sensor followed the same procedure; however the maximum vertical stress applied was $800 \mathrm{kPa}$ to prevent the rupture of the sensor. The compressibility curves measured for the two samples are presented in Figure 7.b for comparison purposes. Their similar shapes indicate that disturbance introduced by the sensor is practically irrelevant. This can be confirmed by comparing the values of compressibility index $C_{c}$, recompressibility index $C_{s}$ and (total) yielding vertical stress found for both tests (Control sample: $C_{c}=0.383, C_{s}=0.029$ and yielding stress 102 MPa; sample with the sensor: $\mathrm{C}_{\mathrm{c}}=0.378, \mathrm{C}_{\mathrm{s}}=0.029$ and yielding stress $118 \mathrm{MPa}$ ).

Figure 8 presents the displacements and the impedance measured during the load step $50-100 \mathrm{kPa}$ to illustrate the behaviour of the sensors under stress increment. The displacements presented are related to the displacement recorded at the beginning of this loading step. In the impedance curve an initial perturbation can be seen, however the values 
become stable after less than one hour. It is not a capacitive effect because voltage was turned on only the time necessary for current to become stable (about two minutes for each reading) in each point measurement. Therefore this may be interpreted as the adjustment of the sensors to the new conditions. After the initial disturbance the values continued changing until they became stable. The time necessary for stabilizing the readings increases with the increment of vertical stresses, but were between $8 \mathrm{~h}$ to $10 \mathrm{~h}$ in all cases. This is considered acceptable for load intervals of $24 \mathrm{~h}$ of duration.

The settlements stabilized before the impedance values (in Figure 8, it took $4 \mathrm{~h}$ for the settlements to become stable, while for the impedance it took about $8 \mathrm{~h}$ ). The changes in impedance along time can be explained by water migration in the soil (probably as vapour) due to the changes in vertical stress. Such analysis is out of the scope of this paper, however. Figure 9 summarizes impedance changes with the vertical stresses applied during the test. It is interesting to note that the shape of the impedance versus vertical stress (and therefore relative humidity vs. vertical stress) is similar to the shape of void ratio vs. vertical stress. This result indicates that the degree of saturation is increasing during compression. In addition, impedance is different for the same vertical stress at loading and unloading. Experimental data show some attempt to recover the initial degree of saturation during unloading. Under the hypothesis that the water content was not changing significantly, this means that relative humidity changes are related with changes in void ratio.

The calibration curve of the sensors may have been affected because void ratio changes during the test. The analysis of how sensors calibration changes with changes in voids ratio is out of the scope of this paper. For simplification, here it is assumed that the calibration of the sensor continued to be valid after the changes in void ratio due to compression (in Table 2, for sensor "Oedometer sensor"). 
The correspondence between the impedance measured and relative humidity inside the soil allowed estimating how relative humidity and suction were changing during loading. Figure 10 presents the correspondence between vertical stress and relative humidity (Fig 10.a), and vertical stress and suction (Figure 10.b).

Suction was computed from the relative humidity using Equation 2. Initial suction was 3.8 $\mathrm{MPa}$ and final suction was $1.66 \mathrm{MPa}, 1.33 \mathrm{MPa}$ being the minimum value found (when the maximum vertical stress was applied). All values are in the suction interval for which the sensors were validated. At the end of the test, suction and water content of the soil around the sensor were measured. Suction measured using WP4-C was 1.42 MPa. The value measured with WP4-C is quite close to that estimated using the sensor, therefore validating its use.

Concerning the water content, the value measured was $11.8 \%$, a value to which the corresponding suction using the WRC is $1.9 \mathrm{MPa}$ using the wetting branch (Figure 7). In reality, the hydraulic path followed should be in the middle of the wetting and drying branches. The wetting branch was chosen because the water content of $11.8 \%$ is slightly larger than the initial water content of $10.3 \%$, even if this initial value was estimated and not measured.

Further studies are necessary for improving the sol-gel sensors performance in order to get accurate suction measurements during the laboratorial tests performed. Nevertheless, the observed trends of water migration during loading and unloading already show the potential of using sol-gel sensors for studying the hydro-mechanical coupled behaviour of soils.

\section{CONCLUSIONS}

The operation interval of the developed sensors was defined to consider the proximity between the WRC measured with WP4 and with the sensors. The measurements were 
acceptable for suction ranges between $1 \mathrm{MPa}$ and $10 \mathrm{MPa}(99.3 \%$ to $92.9 \%)$. This interval extends the actual suction range covered by tensiometers (up to $2 \mathrm{MPa}$ ).

The sensor incorporated in a soil sample tested in oedometeric compression had shown a stable behaviour. Data found showed that the degree of saturation is increasing during compression and there is some decrease during unloading.

Further work will include the optimization of the calibration protocol, considering also different void ratios, and the sol-gel deposition homogeneity. For a robust operation, the protection of sol-gel from clay must be investigated to prevent the clogging of sol-gel pores.

To conclude, this study demonstrates the scientific potential of using microfabricated sensors for the characterization of the hydro-mechanical behaviour of unsaturated soils. A high impact of sol-gel sensors in arbitrary geometry environments is anticipated, because the sensors can be microfabricated into sizes down to $100 \mu \mathrm{m}$, with highly compacted sol-gel coatings.

\section{ACKNOWLEDGEMENTS}

The authors gratefully acknowledge Professor David Toll and Dr Jonathan Asquith from Durham University, UK, for their help using tensiometers. The authors also thank Portuguese Foundation for Science and Technology, FCT, for the financial support provided to the research project EXPL/ECM-GEO/0109/2013. INESC-MN acknowledges FCT funding through the IN Associated Laboratory. G. Sarapajevaite acknowledges ERASMUS+ program through Kaunas University, Lithuania, during her internship. 


\section{REFERENCES}

Albrecht, B., Benson, C., and Beuermann, S. 2003. Polymer capacitance sensors for measuring soil gas humidity in drier soils. Geotechnical Testing Journal, 26 (1), pp. 1-9.

Cardoso, R., Lima, A., Romero, E., and Ferrari, A. 2007. A comparative study of soil suction measurement using two different high-range psychrometers. Experimental Unsaturated Soil Mechanics, Springer Proceedings in Physics, 112, Springer Berlin Heidelberg, pp. 79-94.

Cardoso, R., Sarapajevaite, G., Korsun, O., Cardoso, S., and Ilharco, L. 2016. Sol-gel relative humidity sensors: Impact of electrode geometry on performance in soil suction measurements. Submitted to Sensors and Actuators part A:Chemistry in May 2016.

Fares, A., Abbas, F., Maria, D., and Mair, A. 2011. Improved Calibration Functions of Three Capacitance Probes for the Measurement of Soil Moisture in Tropical Soils. Sensors, 11, pp 4858-4874.

Fredlund, D.G., and Rahardjo, H. 1993. Soil Mechanics for Unsaturated Soils. John Wiley and Sons, New York.

HMT337 2004. Vaisala HUMICAP Humidity and Temperature Transmitter, Series HMT330, USER'S GUIDE, Vaisala.

Jiang, K., Fei, T., and Zhang, T. 2014. Humidity sensor using Li-loaded microporous organic polymer assembled by 1,3,5-trihydroxybenzene and terephthalic aldehydeitle. RSC Adv., 4, pp. 28451-28455.

Keyhani, A. 2001. Development of mini-gypsum blocks for soil moisture measurement and their calibration to compensate for temperature. J. Agric. Sci. Technol., 3, pp. 141-145.

Kizito, F., Campbell, C., Campbell, G., Cobos, D., Teare, B., Carter, B., and Hopmans, J. 2008. Frequency, electrical conductivity and temperature analysis of a low-cost capacitance soil moisture sensor. Journal of Hydrology, 352(3-4), pp. 367-378. 
Kozhukharov, S., Nenova, Z. Nenov, T., Nedev, N., and Machkova, M. 2013. Elucidation of the contribution of modified titania films over the performance of thin film humidity sensors. Journal of Chemical Technology and Metallurgy, 48, 2, pp. 142-146.

Kozhukharov, S., Nenova, Z., Nenov, T., Nedev, N., and Machkova, M. 2015. Humidity sensing elements based on cerium doped titania-silica thin films prepared via a sol-gel method. Sensors and Actuators B 210, pp. 676-684.

Leong, E.-C., Tripathy, S., and Rahardjo, H. 2003 Total suction measurement of unsaturated soils with a device using the chilled-mirror dew-point technique. Géotechnique 53(2), pp $173-182$.

Lourenço, S., Gallipoli, D., Toll, D., Augarde, C., and Evans, F. 2011. Towards a tensiometer based suction control system for laboratory testing of unsaturated soils, Geotechnical Testing Journal, 34, pp. 1-10.

OIML R 121 1996. Organisation Internationale de Métrologie Légale. International Recommendation. The scale of relative humidity of air certified against saturated salt solutions. Grande Imprimerie de Troyes, Troyes, France.

Rittersma, Z.M. 2002. Recent achievements in miniaturizd humidity sensors - a review of transducer techniques. Sensor and Actuators A, 96, pp. 196-210.

Romero, E. 2001. Controlled suction techniques. $4^{\circ}$ Simpósio Brasileiro de Solos Não Saturados, pp. 535-542.

Romero, E. 2013. A microstructural insight into compacted clayey soils and their hydraulic properties. Engineering Geology, 165, pp. 3-19.

Sukhyy, K. M., Gomza. Y. P., Belyanovskaya, E. A., Klepko, V. V., Shilova, O. A., and Sukhyy, M. P. 2015. Resistive humidity sensors based on proton-conducting organicinorganic silicophosphates doped by polyionenes. J Sol-Gel Sci Technol, 74, pp. 472481. 
Tarantino, A., and Mongiovì, L. 2003. Calibration of tensiometer for direct measurement of matric suction, Géotechnique 53(1), pp. 137-141.

Tarantino, A., Gallipoli, D., Augarde, C.E., De Gennaro, V., Gomez, R., Laloui, L., Mancuso, C., El Mountassir, G., Munoz, J.J., Pereira, J.-M., Peron, H., Pisoni, G., Romero, E., Raveendiraraj, A., Rojas, J.A.C, Toll, D.G., Tombolato, S., and Wheeler, S. 2011. Benchmark of experimental techniques for measuring and controlling suction, Geotechnique, 61(4), pp $303-312$.

Traversa, E. 1995. Ceramic sensors for humidity detection: the state-of-the-art and future developments. Sensors and Actuators, B 23, pp. 135-156.

Truong, H.V.P., and Holden, J.C. 1995. Soil Suction Measurement with Transistor Psychrometer. In: Alonso EE, Delage P (eds) Proc 1st Int Conf on Unsaturated Soils (UNSAT 95), Paris. A.A. Balkema, Rotterdam 2, pp. 659-665.

van Genuchten, M. T. 1980. A closed-form equation for predicting the hydraulic conductivity of unsaturated soils. Soil Sci. Soc. Am. J. 44, pp. 892-898.

Vanapalli, S. K., Fredlund, D. G., and Pufahl, D. E. 1999. The influence of soil structure and stress history on the soil-water characteristics of a compacted till. Géotechique, 49, No. 2, pp. 143-159.

Vaz, C., Jones, S., Meding, M., and Tuller, M. 2013. Evaluation of Standard Calibration Functions for Eight Electromagnetic Soil Moisture Sensors. Vadose Zone Journal, 12(2)

Woodburn, J. A., and Lucas, B. 1995 New Approaches to the Laboratory and Field Measurement of Soil Suction. In: Alonso EE, Delage P (eds) Proc 1st Int Conf on Unsaturated Soils (UNSAT 95), Paris. A.A. Balkema, Rotterdam, 2, pp. 667-671.

WP4-C 2003. WP4-C Dew Point PotentiaMeter. Operator's Manual Version 1. Decagon Devices, Inc. 
Yuan, Q., Li, N., Geng, W., Chi, Y., Tu, J., Li, X., and Shao, C. 2011. Humidity sensing properties of mesoporous iron oxide/silica composite prepared via hydrothermal process. Sensors and Actuators B 160, 334-340.

\section{Table Headers}

Table 1 - Details on the samples used for sensors calibration: water content in \% (w), relative humidity $(\mathrm{RH})$ and suction $(s)$.

Table 2 - Calibration curves of the sensors used for the different tests.

\section{Figure Captions}

Figure 1 - Sol-gel sensor developed: a) dimensions; b) 3D scheme (no scale); c) sensor before being used, covered by a heterogeneous white sol-gel layer; d) equilibrium between the solgel and the soil.

Figure 2 - SEM photographs of: a) sol-gel coating; b) compacted clay studied.

Figure 3- Calibration curves considering the average values from 5 sensors, showing reduced hysteresis, and comparison with the curve measured on wetting by a sensor without the solgel cover.

Figure 4 - Soil sample inside a WP4-C cup incorporating the WRC sensor.

Figure 5 - Sensor readings during one drying-wetting cycle: a) impedance versus water content; b) impedance versus suction.

Figure 6 - WRC for the soil, measured by WP4-C and by the sensor. 
Figure 7 - Using the oedometer sensor: a) scheme of the sensor inside the sample; b) compression curves measured in the tests performed with and without the sensor.

Figure 8 - Displacements and impedance evolution along time for the loading step 50 -100 $\mathrm{kPa}$.

Figure 9 - Impedance evolution during the test.

Figure 10 - Data interpretation during the test: a) RH; b) suction. 


\section{FIGURES}

a)
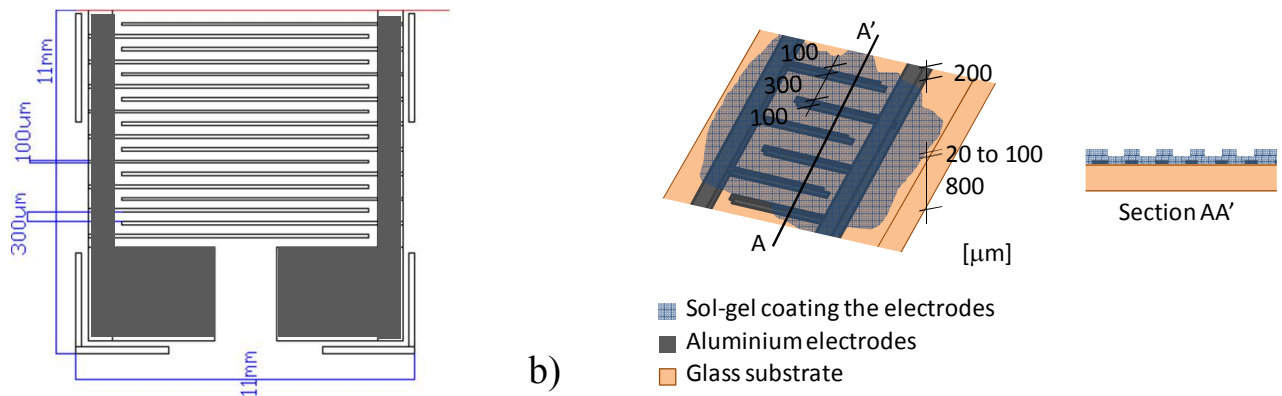

b)

Wol-gel coating the electrodes

Aluminium electrodes

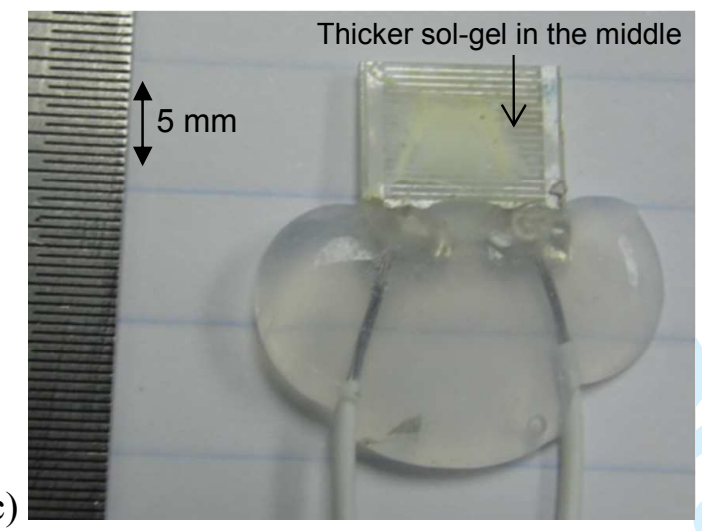

$\square$ Glass substrate

d)

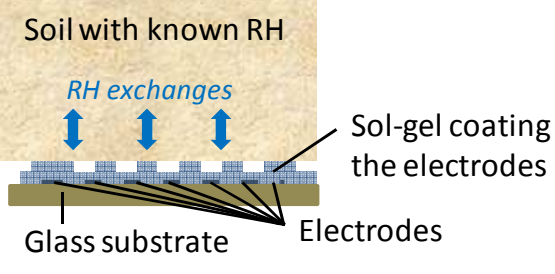

Figure 1 - Sol-gel sensor developed: a) dimensions; b) 3D scheme (no scale); c) sensor before being used, covered by a white sol-gel layer; d) equilibrium between the sol-gel and the soil. 


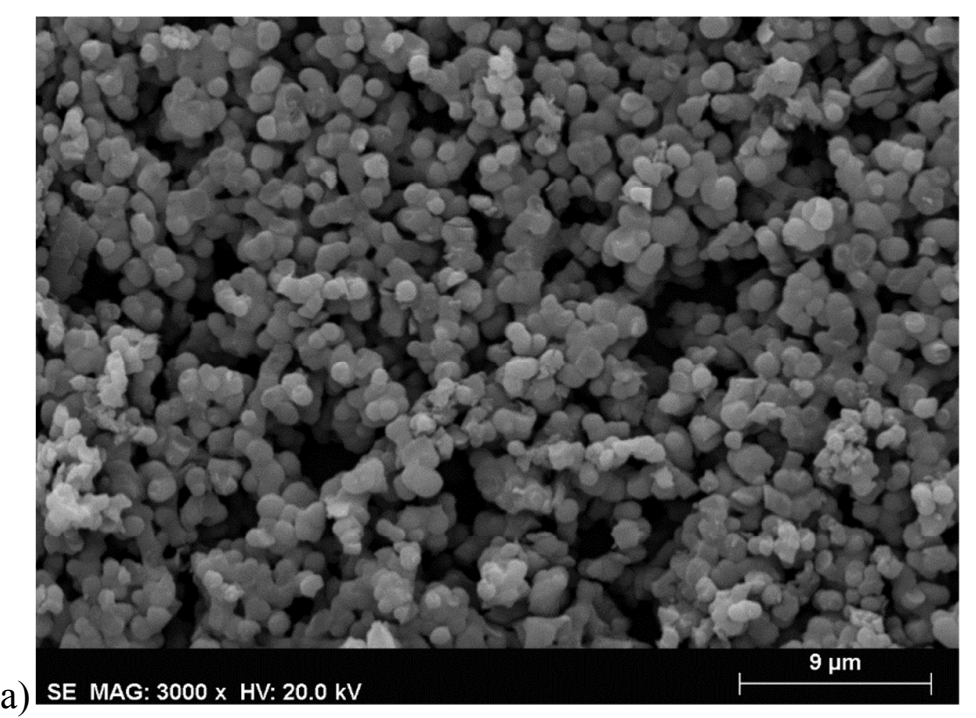

a) Se mact

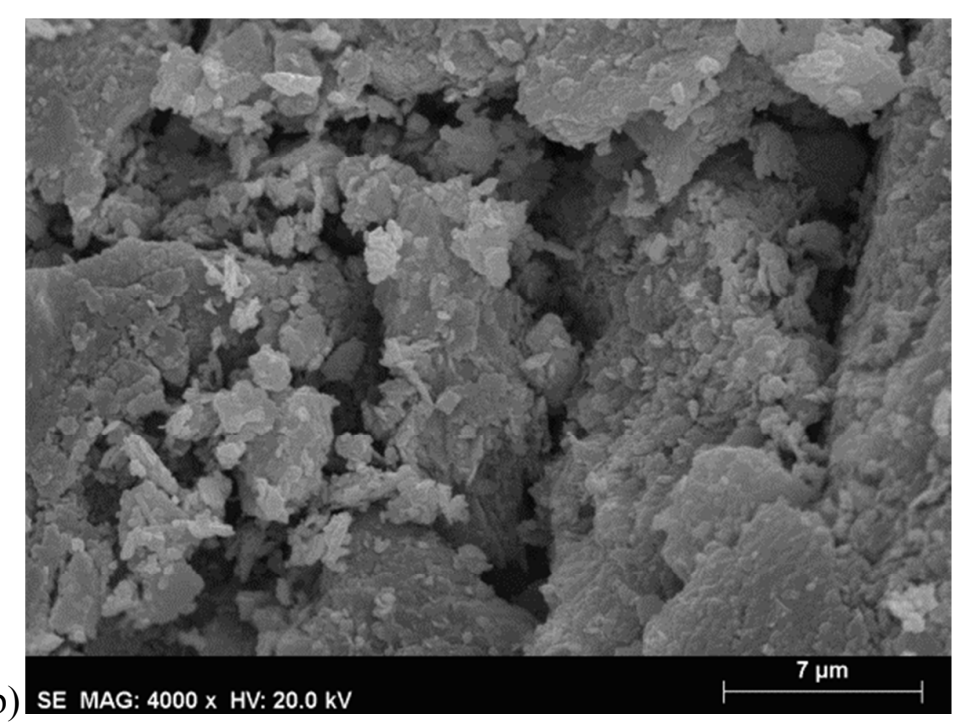

Figure 2 - SEM photographs of a) sol-gel coating; b) compacted clay studied. 


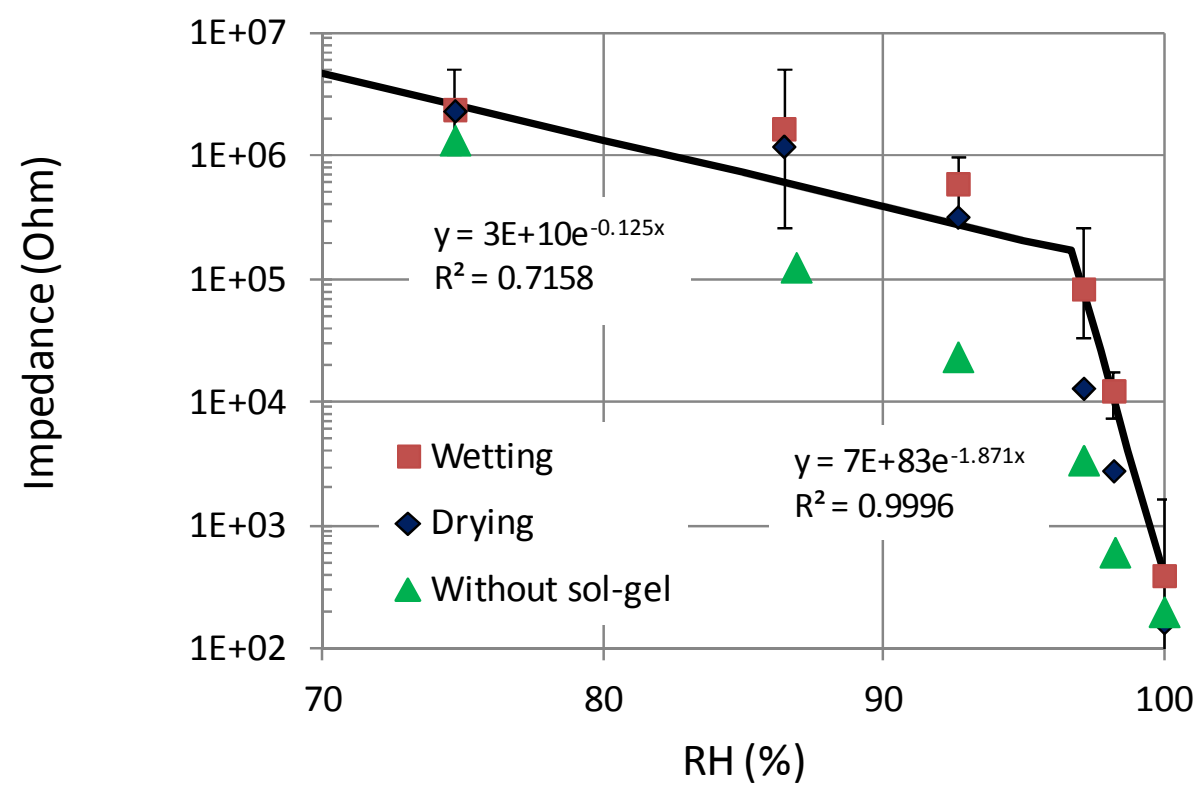

Figure 3-Calibration curves considering the average values from 5 sensors, showing reduced hysteresis, and comparison with the curve measured on wetting by a sensor without the sol-gel cover. 


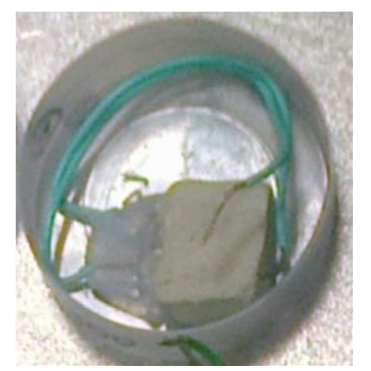

Figure 4 - Soil sample inside a WP4-C cup incorporating the WRC sensor. 


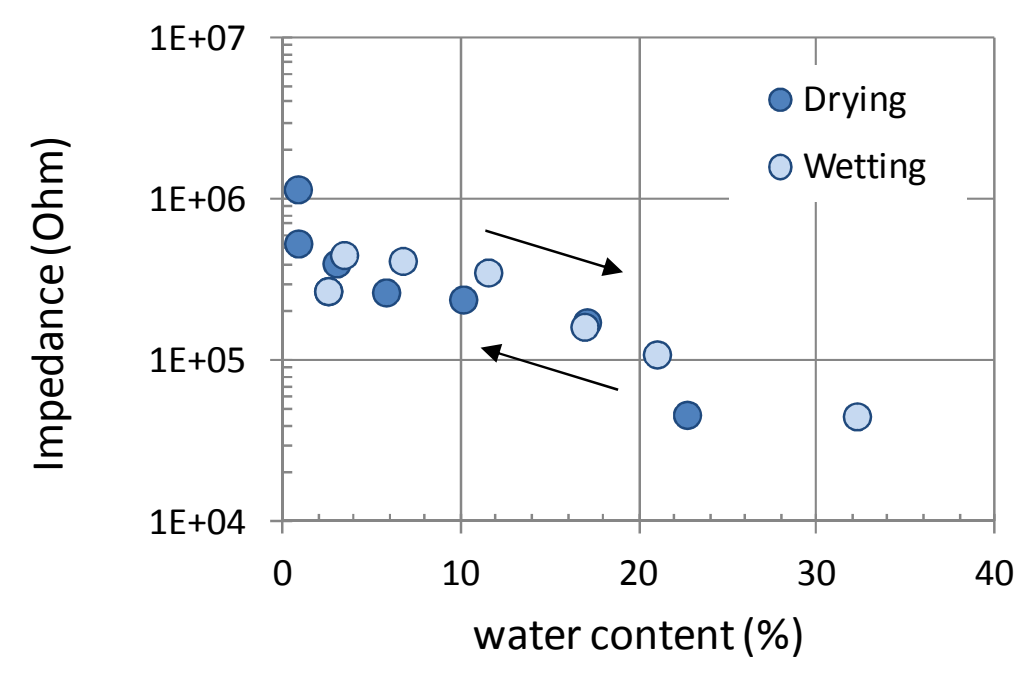

a)

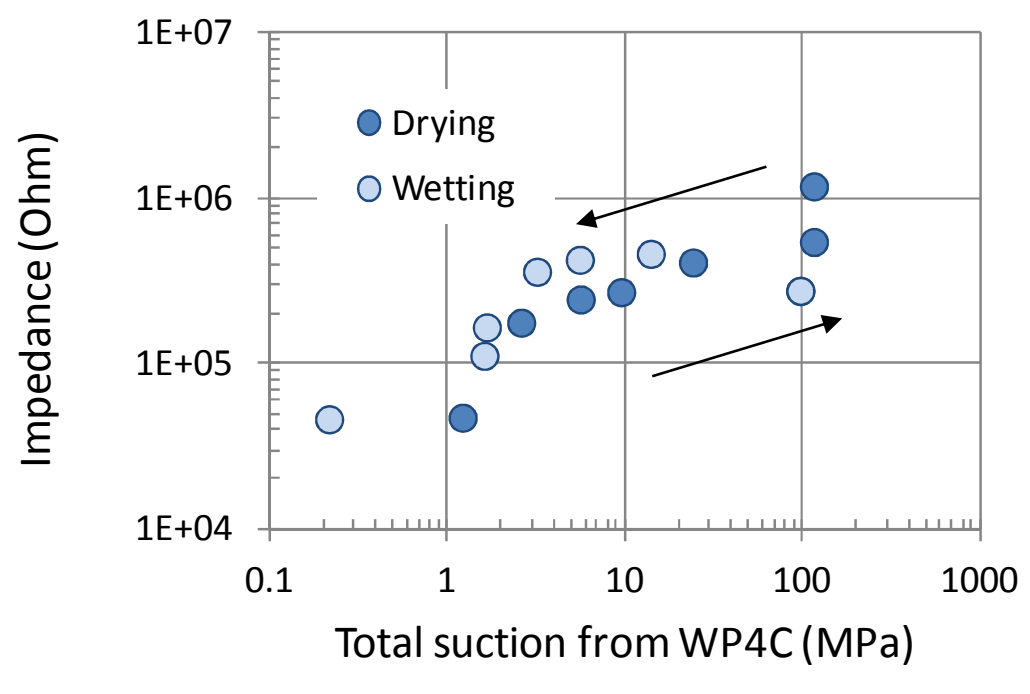

b)

Figure 5 - Sensor readings during one drying-wetting cycle: a) impedance versus water content; $b$ ) impedance versus suction. 


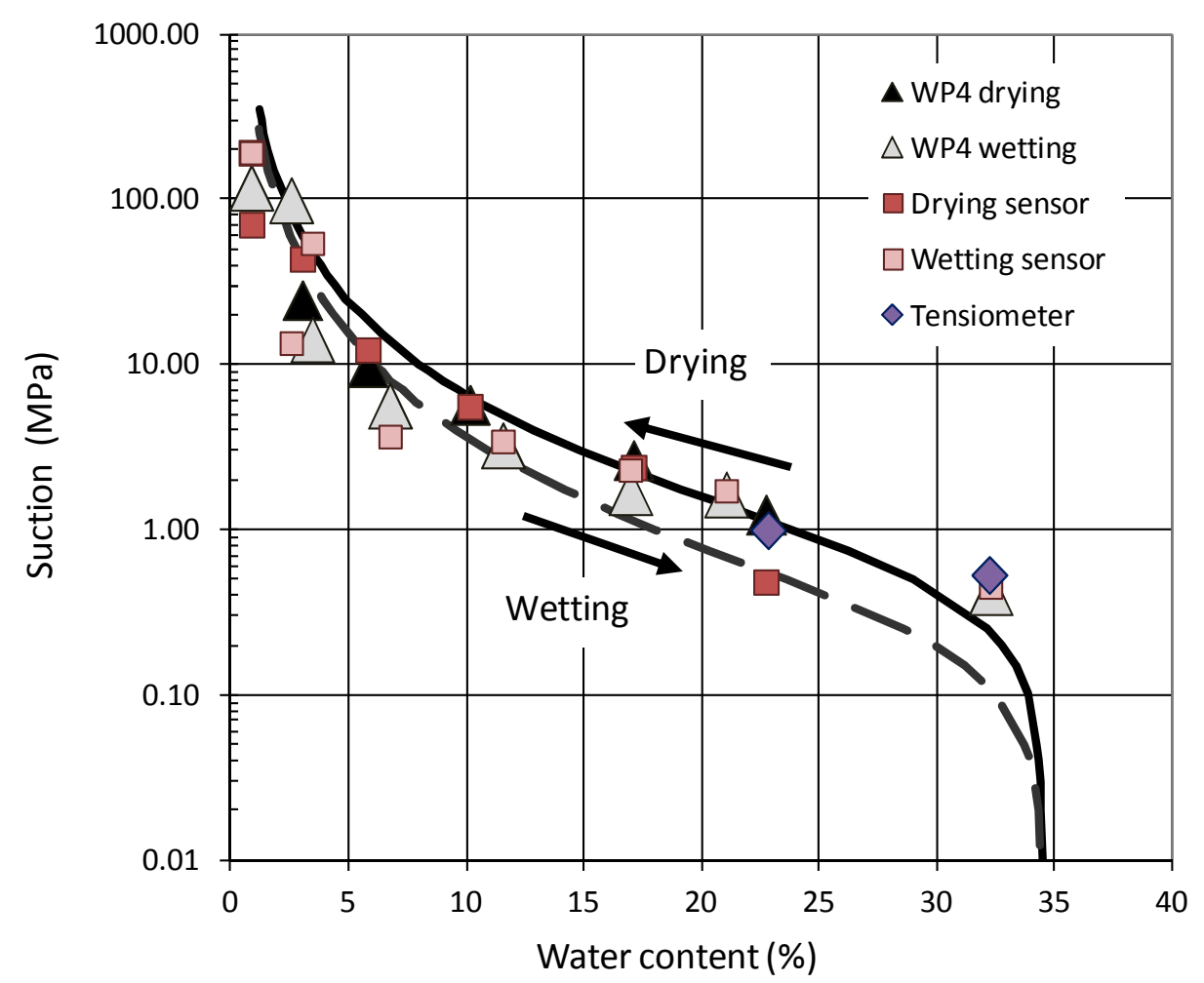

Figure 6 - WRC for the soil, measured by WP4-C and by the sensor. 
a)
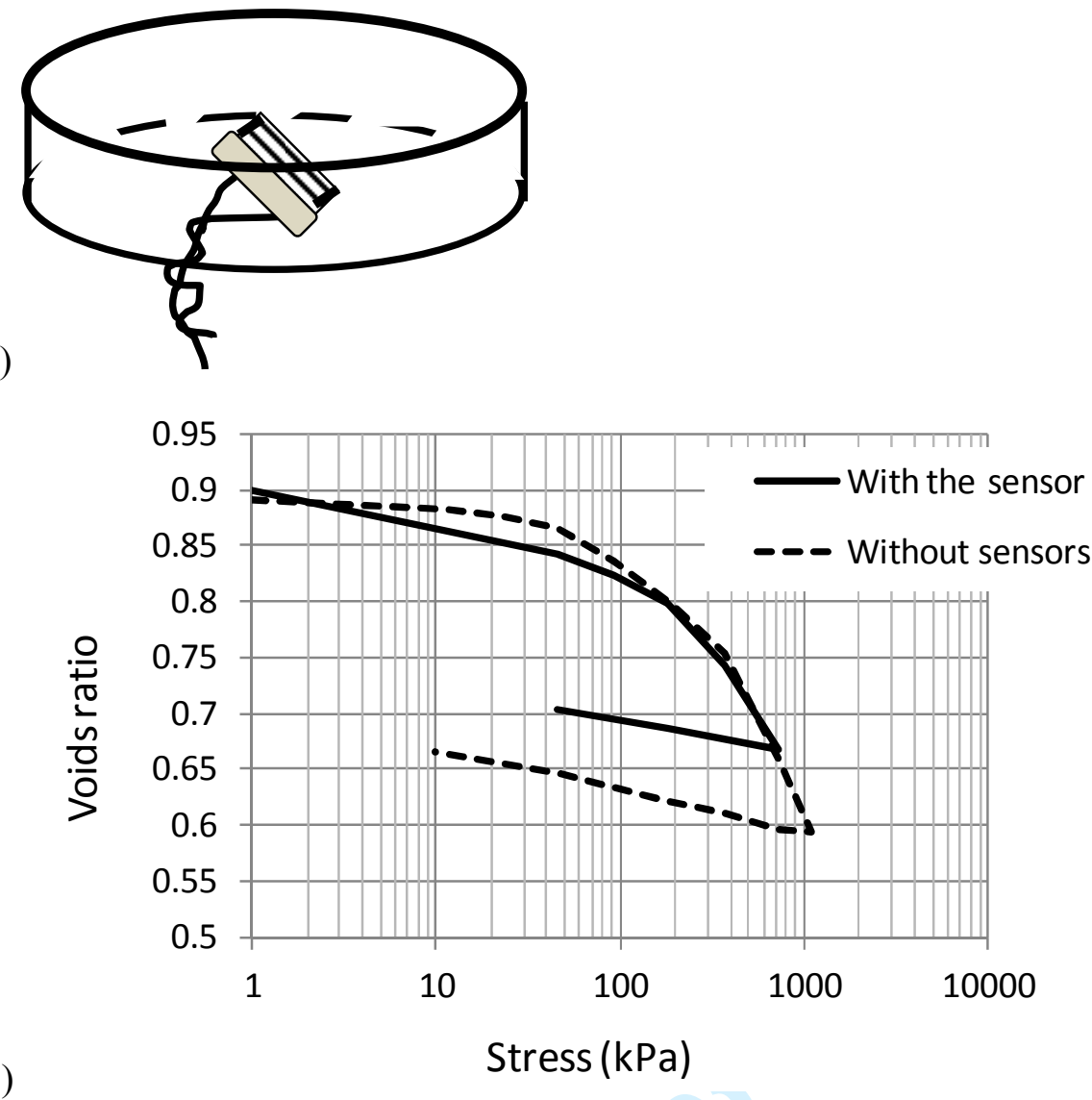

Figure 7 - Using the oedometer sensor: a) scheme of the sensor inside the sample; b) compression curves measured in the tests performed with and without the sensor. 

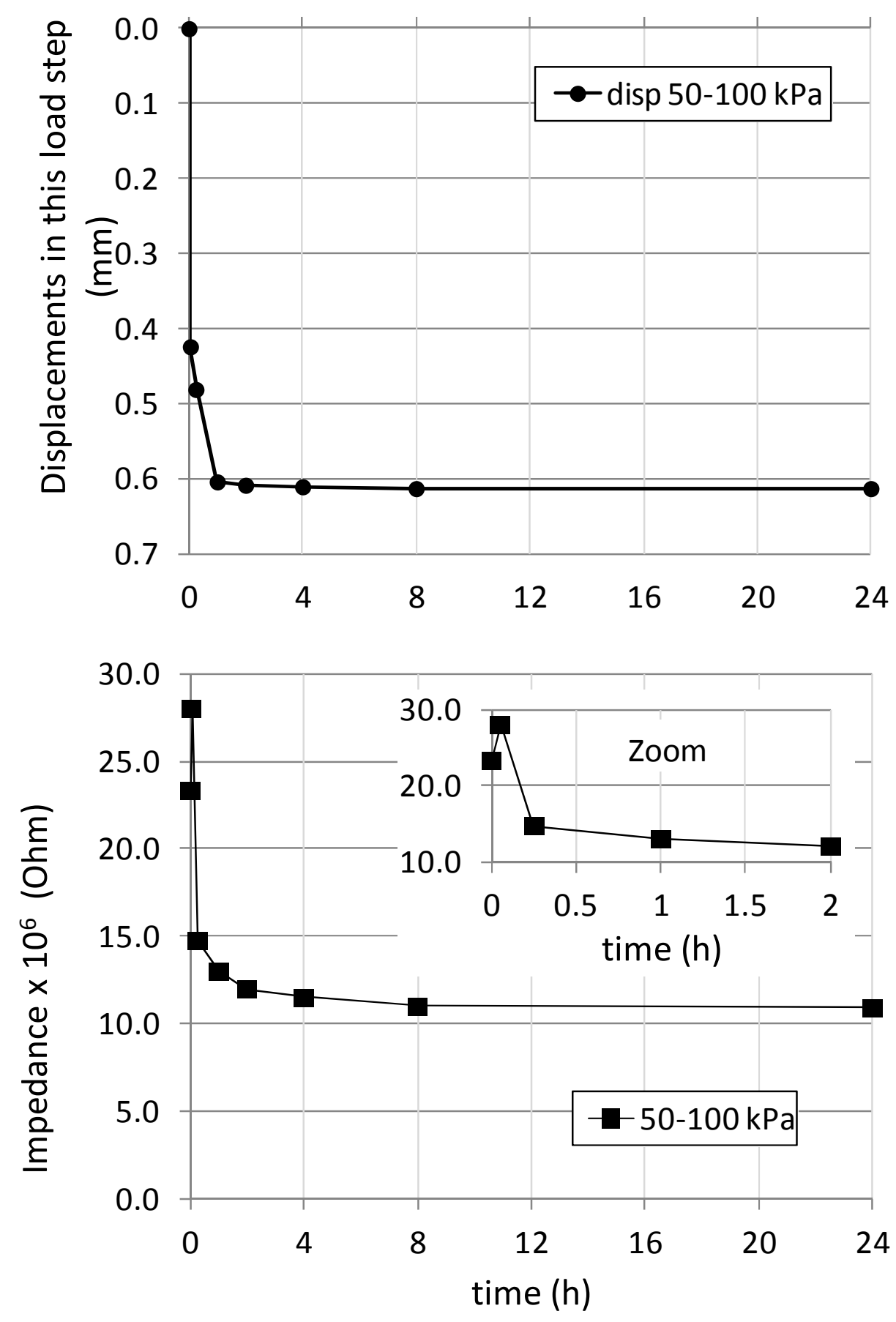

Figure 8 - Displacements and impedance evolution along time for the loading step $50-100 \mathrm{kPa}$. 


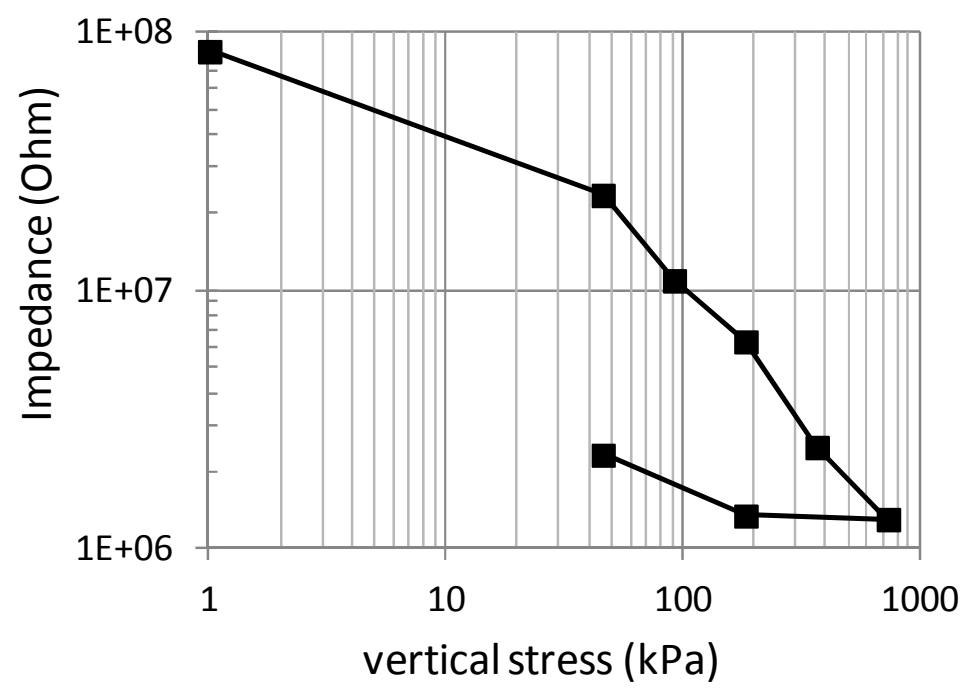

Figure 9 - Impedance evolution during the test. 


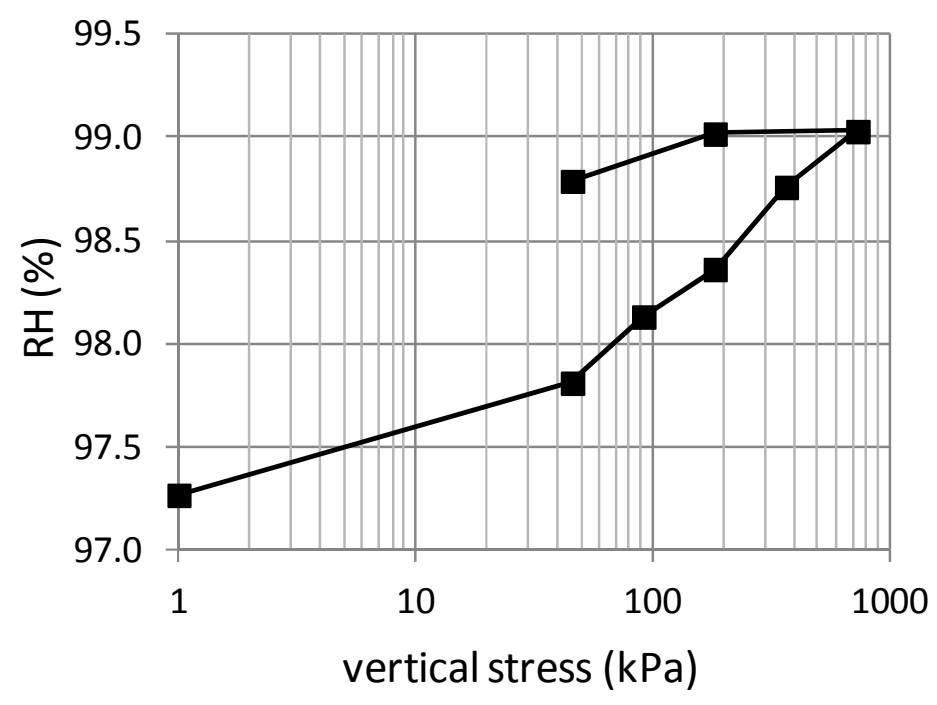

a)

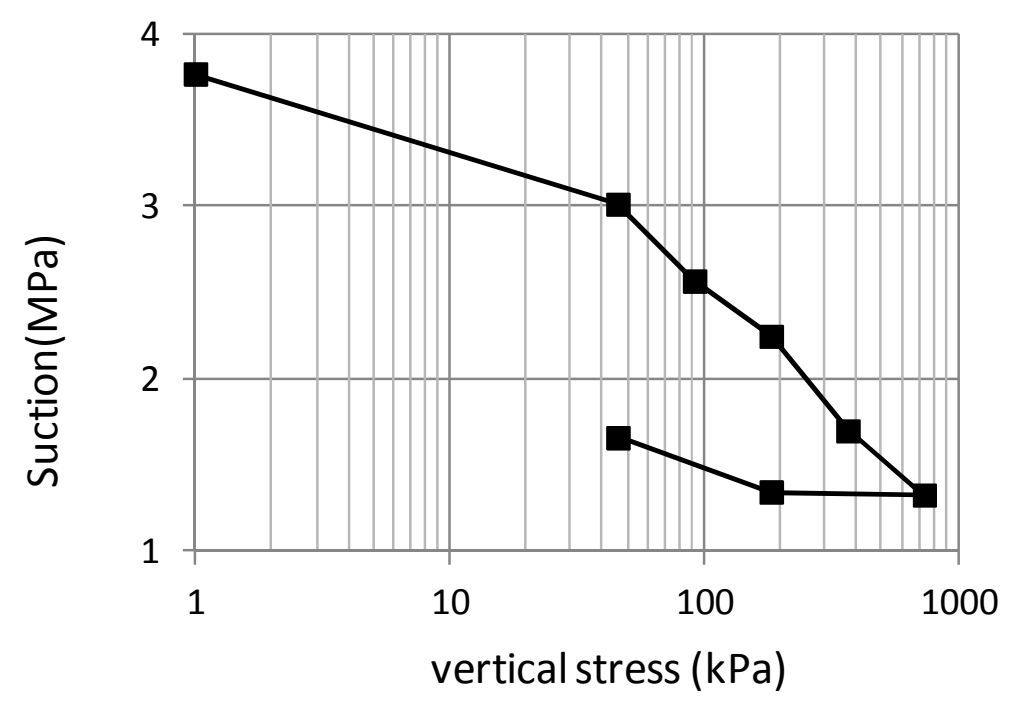

Figure 10 - Data interpretation during the test: a) RH; b) suction. 


\section{TABLES}

Table 1 - Details on the samples used for sensors calibration: water content in $\%(\mathrm{w})$, relative humidity $(\mathrm{RH})$ and suction $(s)$.

\begin{tabular}{|l|l|l|l|l|l|l|l|}
\hline & \multicolumn{7}{|c|}{ SAMPLE } \\
\hline w (\%) & 1.9 & 2.6 & 3.9 & 6.4 & 8.7 & 16.2 & 34.3 \\
\hline RH (\%) & 69.5 & 86.4 & 92.6 & 94.3 & 98.2 & 98.6 & 100 \\
\hline$s(\mathrm{MPa})$ & 49.12 & 19.74 & 10.38 & 7.92 & 2.45 & 1.90 & - \\
\hline
\end{tabular}

Table 2 - Calibration curves of the sensors used for the different tests.

\begin{tabular}{|l|l|l|l|}
\hline & \multicolumn{1}{|c|}{ Low $\mathrm{RH}$} & \multicolumn{1}{c|}{ High $\mathrm{RH}$} & $\begin{array}{c}\mathrm{RH} \text { at the transition } \\
\text { (suction in MPa) }\end{array}$ \\
\hline WRC sensor & $\begin{array}{l}\mathrm{I}=2 \mathrm{E}+06 \mathrm{e}^{-0.022 R H} \\
\mathrm{R}^{2}=0.5668\end{array}$ & $\begin{array}{l}\mathrm{I}=9 \mathrm{E}+45 \mathrm{e}^{-0.954 R H} \\
\mathrm{R}^{2}=0.8388\end{array}$ & $97.9 \%(2.87)$ \\
\hline Oedometer sensor & $\begin{array}{l}\mathrm{I}=6 \mathrm{E}+11 \mathrm{e}^{-0.076 R H} \\
\mathrm{R}^{2}=0.9951\end{array}$ & $\begin{array}{l}\mathrm{I}=4 \mathrm{E}+108 \mathrm{e}^{-2.369 R H} \\
\mathrm{R}^{2}=0.9190\end{array}$ & $97.2 \%(3.85)$ \\
\hline
\end{tabular}

